\title{
PD-L1 expression in malignant pleural effusion samples and its correlation with oncogene mutations in non-small cell lung cancer
}

\author{
Zhengbo Song ${ }^{1}$, Guoping Cheng ${ }^{2}$, Yiping Zhang ${ }^{1}$ \\ ${ }^{1}$ Department of Medical Oncology, ${ }^{2}$ Department of Pathology, Zhejiang Cancer Hospital, Hangzhou 310022, China \\ Contributions: (I) Conception and design: Z Song; (II) Administrative support: Y Zhang; (III) Provision of study materials or patients: Z Song; (IV) \\ Collection and assembly of data: G Cheng; (V) Data analysis and interpretation: Z Song; (VI) Manuscript writing: All authors; (VII) Final approval of \\ manuscript: All authors. \\ Correspondence to: Zhengbo Song, MD. Department of Chemotherapy, Zhejiang Cancer Hospital, Guangji Road No. 38, Hangzhou 310022, China. \\ Email: songzhengbo83@163.com.
}

\begin{abstract}
Background: Programmed death ligand 1 (PD-L1) tumor proportion score (TPS) is currently widely used for selection of immune therapies in non-small cell lung cancer (NSCLC). Most of samples for PDL1 expression were obtained from tumor tissue. However, the feasible of malignant pleural effusion (MPE) cytological samples for PD-L1 detection is poorly reported. And the correlation between oncogene mutations and PD-L1 expression based on high-throughput sequencing is rarely studied.

Methods: NSCLC MPE cytological samples and partially paired tumor tissue from our institution analyzed for PD-L1 immunohistochemistry (IHC) using the clone SP263 pharmDx kit and evaluated genomic aberrations in all patients using next generation sequencing (NGS).

Results: One hundred and twenty-three MPE cell blocks and 29 paired tumor tissue were successfully tested for PD-L1 expression. PD-L1 TPS of $\geq 50 \%$ were seen in $18.7 \%$ (23/123) of all samples. The accordance of PD-L1 expression in tumor tissue and MPE samples was $86.2 \%$ (50\% as cut-off value). PD-L1 TPS $\geq 50 \%$ tumors were significantly associated with $E G F R$ wild-type ( $\mathrm{P}=0.007)$, but, no correlation between other genes and PD-L1 expression. A trend of longer overall survival (OS) was observed in patients with PDL1 TPS $<50 \%$ than those TPS $\geq 50 \%$ (20.0 vs. 13.8 months, $\mathrm{P}=0.057$ ). No difference of tumor mutational burden (TMB) was observed between patients with PD-L1 $\geq 50 \%$ and $<50 \%(8.2 / \mathrm{MB}$ and 7.7/MB, $\mathrm{P}=0.47)$.

Conclusions: Our results suggest that cytological material is feasible for PD-L1 IHC analysis. Gene alterations could partially contribute to select the samples that with different PD-L1 expression. No correlation between the PD-L1 expression and TMB.
\end{abstract}

Keywords: Tumor proportion score (TPS); malignant pleural effusion (MPE); programmed death ligand 1 (PDL1); oncogene mutations

Submitted Sep 22, 2019. Accepted for publication Oct 26, 2019.

doi: $10.21037 /$ jtd.2020.02.06

View this article at: http://dx.doi.org/10.21037/jtd.2020.02.06

\section{Introduction}

Patients of advanced non-small cell lung cancer (NSCLC) harbored EGFR, ALK and ROS1 improved the overall survival (OS) and quality of life after the molecular targeted therapy (1-6). However, the survival in patients with wildtype of gene alternations was not improved recently. The anti-programmed death 1 (PD-1) and programmed death ligand 1 (PD-L1) immune checkpoint inhibitors, have been approved for systemic therapy in advanced NSCLC for remarkable efficacy compared with chemotherapy, especially in patients with PD-L1 tumor proportion scores (TPSs) of $\geq 50 \%$ (7-9). However, many questions are not well answered currently (10). PD-L1 detection was mostly based on tumor tissue in previous studies. It is not well known that whether the cytological samples could be used for PD-L1 detection. The relationship between EGFR/ALK 
mutations and PD-L1 expression was clearly investigated, while, the data based on high-throughput sequencing was scarce.

In present study, 123 malignant pleural effusion (MPE) samples were retrospectively analyzed for PD-L1 expression. Meanwhile, all of the samples were detected gene alterations with next generation sequencing (NGS) containing 416 genes. We aim to expound the feasibility of MPE samples for PD-L1 detection and investigate the correlation between oncogene mutations and PD-L1 expression.

\section{Methods}

\section{Sample selection}

Patients were enrolled in the study between Aug 2015 and Dec 2016. Eligible patients were aged at least 18 years and had advanced, non-squamous NSCLC with pleural effusion. All of the pleural effusion samples were confirmed as malignant by cytological smears. At the time of enrollment, the patients had not received targeted inhibitors. Patient exclusion criteria included squamous cell lung cancer, small cell lung cancer, or other metastatic malignancies tumor to the lung. Diagnosis of the tumors was performed by institutional pathologists with the accordance of the 2015 WHO classification. The study was approved by Zhejiang Cancer Hospital Ethics Committee (IRB201403-032). Written informed consent was obtained from all participants.

\section{Preparation of cell block and tumor PD-L1 analysis}

About $50-\mathrm{mL}$ fluid specimens were centrifuged at 2,500-3,000 rpm for $5 \mathrm{~min}$. Cell sediments were then harvested, fixed with 3 times the volume of $10 \%$ neutralbuffered formalin for $60 \mathrm{~min}$, wrapped in filter paper, and processed in an automatic tissue processor. The samples were embedded in paraffin and sectioned at a thickness of 4-5 mm.

Ventana independently stained all cases using PD-L1 IHC assay platforms. At Ventana, sections were stained with anti-PD-L1 (SP263, Roche) rabbit monoclonal primary antibody and a matched rabbit immunoglobulin G-negative control with an OptiView DAB IHC Detection Kit on the BenchMark ULTRA automated staining platform. Three pathologists were independently evaluated all PD-L1 immunostained slides.

\section{NGS analysis}

Cell blocks were obtained and shipped to the central testing laboratory by required conditions. The tests were performed in Nanjing Geneseeq Technology Inc., China. Briefly, DNA was extracted from formalin-fixed, paraffin-embedded (FFPE) samples. Purified DNA was qualified by Nanodrop2000 (Thermo Fisher Scientific) and quantified by Qubit 3.0 using the dsDNA HS Assay Kit (Life Technologies) according to the manufacturer's recommendations. Sequencing libraries were prepared using the KAPA Hyper Prep kit (KAPA Biosystems) with an optimized manufacturer's protocol. Customized xGen lockdown probes (Integrated DNA Technologies) targeting 416 cancer-relevant genes were used for hybridization enrichment (Table S1). The capture reaction was performed with the NimbleGen SeqCap EZ Hybridization and Wash Kit (Roche) and Dynabeads M-270 (Life Technologies) with optimized manufacturers' protocols. Genomic fusions were identified by FACTERA with default parameters. Copy number variations (CNVs) were detected using ADTEx (http://adtex.sourceforge.net) with default parameters. Somatic CNVs were identified using paired normal/tumor samples for each exon.

TMB was defined as the number of somatic, coding, base substitution, and indel mutations per megabase of genome examined. For our panel TMB calculation, all base substitutions, including non-synonymous and synonymous alterations, and indels in the coding region of targeted genes were considered with the exception of known hotspot mutations in oncogenic driver genes and truncations in tumor suppressors. Synonymous mutations were counted in order to reduce sampling noise and known driver mutations were excluded as they are over-represented in the panel, as previously described (11).

\section{Statistical methods}

Fisher's exact test was used to compare categorical variables. All $\mathrm{P}$ values reported are two-sided, and tests were conducted at the 0.05 significance level. The relationship between different groups was analyzed with chi-square tests. Progression-free survival (PFS) with targeted therapy was defined as the time from initiation targeted treatment to documented progression or death from any cause. PFS was plotted by the Kaplan-Meier method. All analyses were performed using SPSS ${ }^{\circledR}$ version 18.0 (SPSS Inc., Chicago, IL, USA). The last follow-up date was May 31, 2018. 
Table 1 Clinicopathological characteristics of study participants

\begin{tabular}{lc}
\hline Variable & Number (\%) \\
\hline Gender & $65(52.8)$ \\
Male & $58(47.2)$ \\
Female & \\
Age (years) & $46(37.4)$ \\
$\geq 65$ & $77(62.6)$ \\
$<65$ & \\
Smoking history & $51(41.5)$ \\
Yes & $72(58.5)$ \\
No & \\
Performance status & $106(86.2)$ \\
$0-1$ & $17(13.8)$ \\
2 & \\
Metastatic status & \\
M1a & $73(59.3)$ \\
M1b & $50(40.7)$ \\
Histology & \\
Nononocarcinoma & \\
\hline No & \\
\hline
\end{tabular}

The median follow-up time was 20.2 months (range, 3.029.5 months). No patients were lost to follow-up.

\section{Results}

\section{Baseline clinical and pathologic characteristics}

Of the 123 patients analyzed, 65 were male and 58 of female with median age of 59 years old (range, 33 to 81 years old). Most of patients were with histology of adenocarcinoma (119 of 123). Fifty-one patients had smoking history and 72 were never smokers. The details of clinical and pathologic characteristics in present study were listed in Table 1.

\section{PD-L1 expression in MPE samples and paired tumor tissues}

Totally, 48 (39.0\%) were with PD-L1 negative, followed by
$1-5 \%(n=28)$, and PD-L1 TPSs of 5-49\% ( $\mathrm{n}=24)$. Twentythree were with proportion of PD-L1 TPS of $\geq 50 \%$. PDL1 TPS $\geq 50 \%$ was seen significantly more frequently in smokers as compared to never smokers $(\mathrm{P}=0.01)$ and males $(\mathrm{P}=0.025)$. While not associated with patient tumor stage $(\mathrm{P}=0.53)$, age $(\mathrm{P}=0.85)$ and performance status $(\mathrm{P}=0.33)$ (Table S2).

Twenty-nine patients were obtained the paired tumor tissue and with PD-L1 IHC detection (Figure 1). Among the 29 samples, 14 had PD-L1 TPS $\geq 1 \%$ in tumor tissue, and 11 in paired MPE samples, with agreement statistics of $69.0 \%$ (20/29) (Table 2). When $50 \%$ as cut off value, the accordance between MPE samples and tumor tissue was $86.2 \%(25 / 29)$ (Table 3). The details of comparison between MPE samples and tumor tissue was presented in Tables 2-4.

\section{NGS results}

All results of the comparative analyses are presented in Figure 2. Overall, EGFR mutations were with most frequent (55.3\%), followed with TP53 mutation (51.2\%). Sixteen patients were found to harbor KRAS mutations, ALK rearrangement were observed in 11 patients. There was no ROS1 rearrangement, MET amplification and exon 14 skipping among the 123 samples.

\section{Association between PD-L1 expression and oncogene aberrations}

Of the 68 patients with EGFR mutations, $10.3 \%$ of PD-L1 TPS $\geq 50 \%$, while, the percentage of PD-L1 TPS $\geq 50 \%$ was $29.1 \% E G F R$ wild-type $(\mathrm{P}=0.007)$. Of 11 patients with $A L K$ rearrangement, 9 had PD-L1 TPS $<50 \%$, as compared with only two tumors with PD-L1 TPS $\geq 50 \%$ ( $\mathrm{P}=0.72$ ). More patients with PD-L1 TPS $\geq 50 \%$ in KRAS mutations than wild-type samples $(25.0 \%$ vs. $17.8 \%, \mathrm{P}=0.73)$ (Table 5 and Figure 51 ). The median TMB in samples with $\mathrm{PD}-\mathrm{L} 1 \geq 50 \%$ and $<50 \%$ was $8.2 / \mathrm{MB}$ and $7.7 / \mathrm{MB}$, respectively $(\mathrm{P}=0.47)$.

\section{PD-L1 expression and clinical treatment}

Forty-seven patients with EGFR mutations received EGFRTKIs treatment. The median PFS was 10.2 months (95\% CI: 9.1-11.7 months). A trend of longer PFS was observed in patients with PD-L1 TPS $\geq 50 \%$ (11.7 vs. 9.7 months, $\mathrm{P}=0.17)$. Forty-four patients received first-line platinumbased chemotherapy, including 25 with pemetrexed and 19 

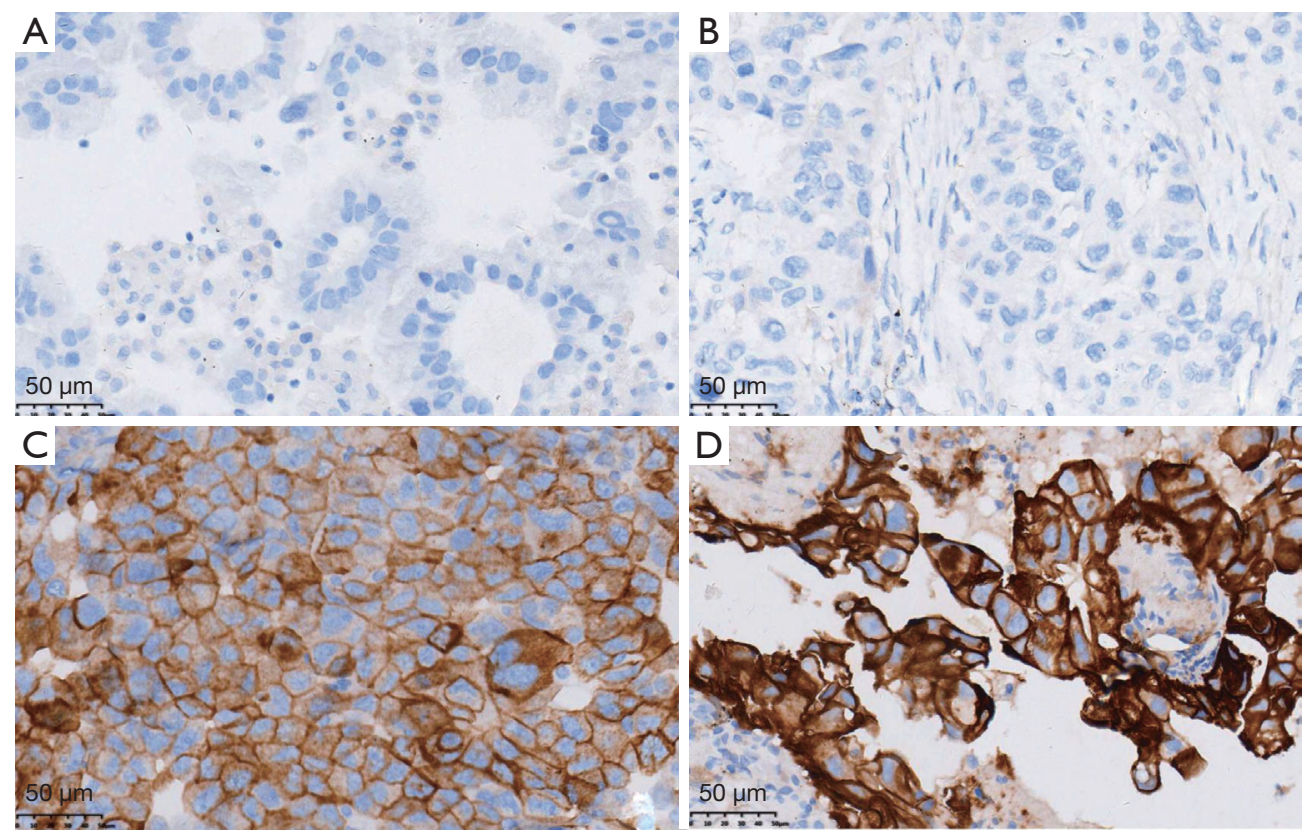

Figure 1 PD-L1 expression in MPE samples (A,C) and paired tumor tissue (B,D) (A and B: TPS =0\%; C and D: TPS =100\%; IHC, x400). PD-L1, programmed death ligand 1; MPE, malignant pleural effusion; TPS, tumor proportion score; IHC, immunohistochemistry.

Table 2 PD-L1 expression in tumor tissue and paired MPE samples (a cut-off value of $1 \%$ )

\begin{tabular}{lccc}
\hline \multirow{2}{*}{ MPE } & \multicolumn{2}{c}{ Tumor tissue } & Total \\
\cline { 2 - 3 } & Positive & Negative & \\
\hline Positive & 8 & 3 & $11(37.9)$ \\
Negative & 6 & 12 & $18(62.1)$ \\
Total & $14(48.3)$ & $15(51.7)$ & 29 \\
\hline
\end{tabular}

PD-L1, programmed death ligand 1; MPE, malignant pleural effusion.

Table 3 PD-L1 expression in tumor tissue and paired MPE samples (a cut-off value of 50\%)

\begin{tabular}{lccc}
\hline \multirow{2}{*}{ MPE } & \multicolumn{2}{c}{ Tumor tissue } & Total \\
\cline { 2 - 3 } & Positive & Negative & \\
\hline Positive & 5 & 1 & $6(20.7)$ \\
Negative & 3 & 20 & $23(79.3)$ \\
Total & $8(27.6)$ & $21(72.4)$ & 29 \\
\hline
\end{tabular}

PD-L1, programmed death ligand 1; MPE, malignant pleural effusion.
Table 4 PD-L1 expression in tumor tissue and paired MPE samples (a cut-off value of $10 \%$ )

\begin{tabular}{lccc}
\hline \multirow{2}{*}{ MPE } & \multicolumn{2}{c}{ Tumor tissue } & \multirow{2}{*}{ Total } \\
\cline { 2 - 3 } & Positive & Negative & \\
\hline Positive & 8 & 1 & $9(31.0)$ \\
Negative & 4 & 16 & $20(69.0)$ \\
Total & $12(41.4)$ & $17(58.6)$ & 29 \\
\hline
\end{tabular}

PD-L1, programmed death ligand 1; MPE, malignant pleural effusion.

of other regimens. No PFS difference was found between different regimens (7.0 vs. 6.5 months, $\mathrm{P}=0.97$ ).

The median OS of all patients was 18.4 months (95\% CI: 14.9-21.8 months). A trend of longer OS was observed in patients with PD-L1 TPS $<50 \%$ than those TPS $\geq 50 \%$ (20.0 vs. 13.8 months, $\mathrm{P}=0.057$ ) (Figure 3). No survival difference was observed in EGFR/ALK positive patients with PD-L1 TPS $<50 \%$ than those TPS $\geq 50 \%$ (21.0 vs. 20.5 months, $\mathrm{P}=0.21$ ); However, a shorter survival was existed in EGFR/ $A L K$ negative patients with PD-L1 TPS $<50 \%$ than those 


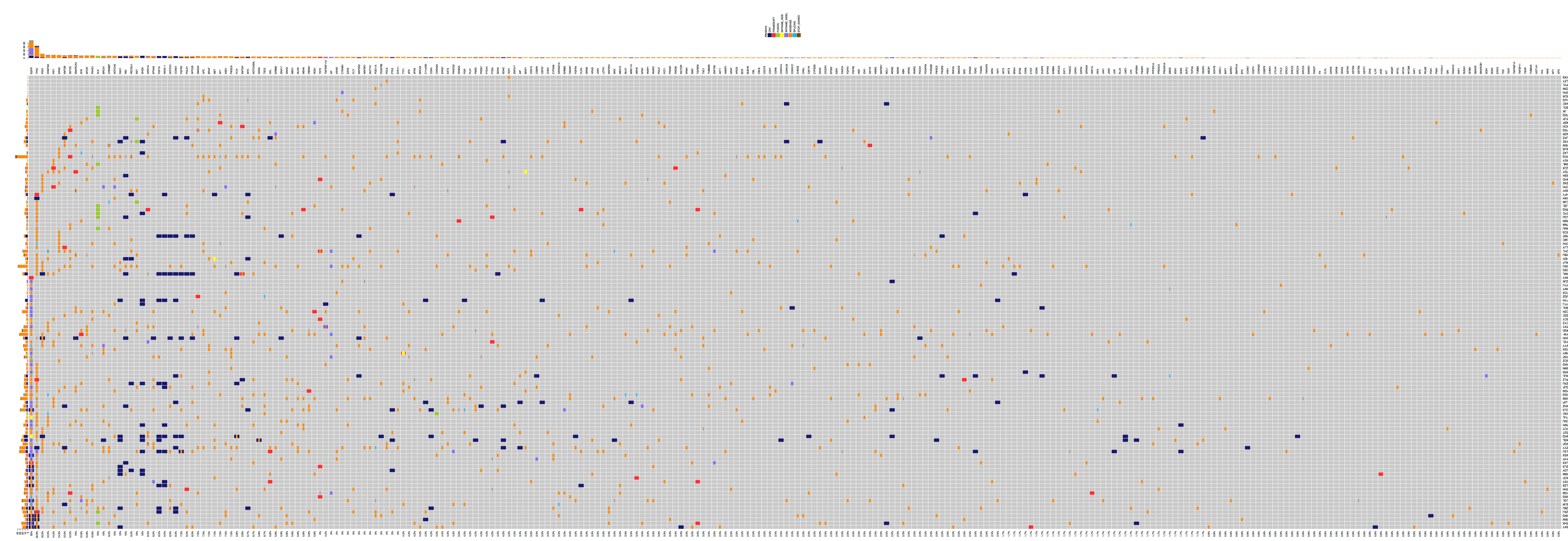


Table 5 Correlation between common oncogene mutations or rearrangement and PD-L1 over-expression

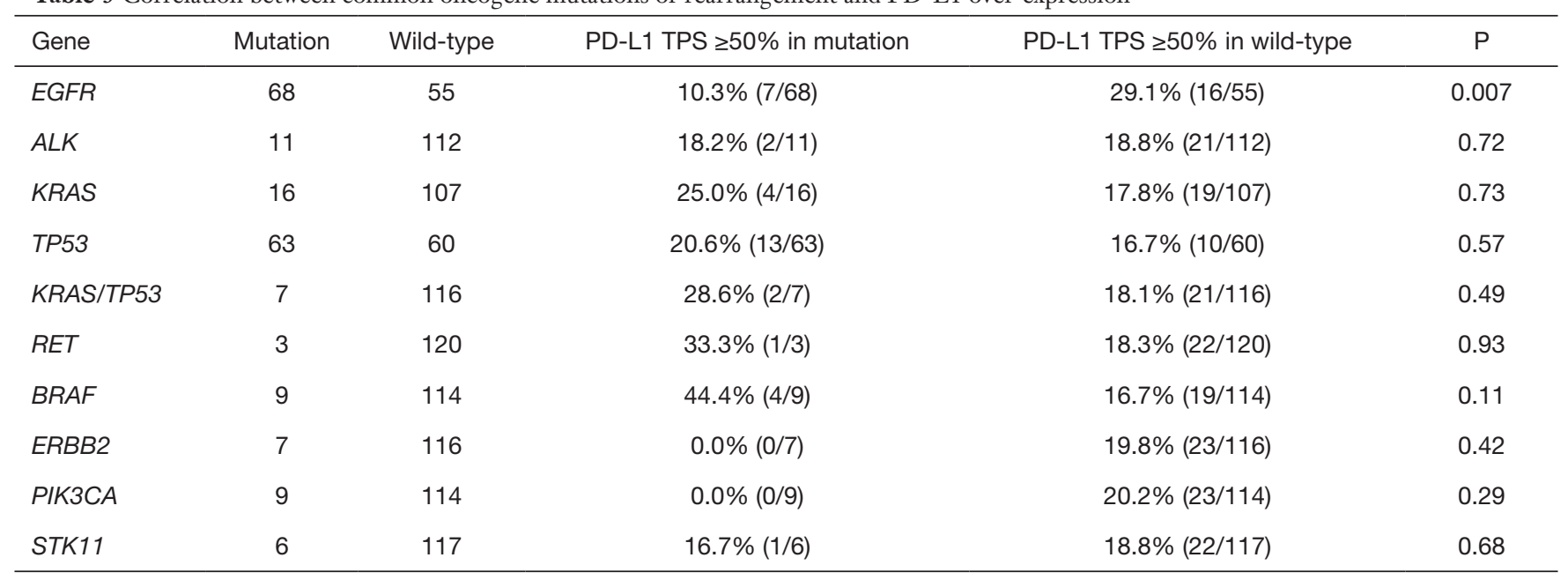

PD-L1, programmed death ligand 1; TPS, tumor proportion score.

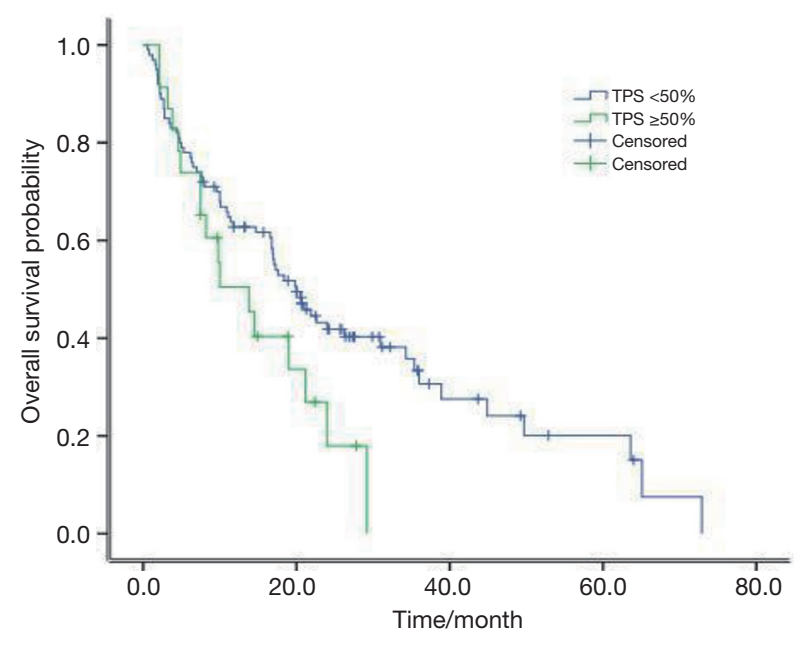

Figure 3 Overall survivals comparison in patients with different PD-L1 expression. PD-L1, programmed death ligand 1.

TPS $\geq 50 \%$ (15.5 vs. 12.7 months, $\mathrm{P}=0.025)$.

\section{Discussion}

A high accordance of PD-L1 expression was found between tumor tissue and cytological samples in present study. Further, we investigated the relationship between gene alternations and PD-L1 expression based on highthroughput sequencing. Our results demonstrated PD-L1 expression was associated with some oncogene aberrations.

Two platforms are currently applied in clinical practice for PD-L1 IHC detection, including DAKO and VENTANA (12-14). Patients with PD-L1 TPS of $\geq 50 \%$ were reported to benefit more from pembrolizumab treatment than chemotherapy in KEYNOTE024 study (7). And the PD-L1 TPS of $\geq 50 \%$ were reported in $20 \%$ to $30 \%$ of advanced NSCLC (7-9). The difference percentage may contribute to different antibodies in different trials. The Blueprint PD-L1 IHC Assay Comparison Project revealed that three antibodies $(22 \mathrm{C} 3,28-8$, SP263) were closely aligned on tumor cell staining, but different from SP142 (15). In present study, The PD-L1 TPS of $\geq 50 \%$ were found in $18.7 \%$ patients, which was a similar percentage compared with previous studies (16-18). And a high correlation between staining on cytological cell block material and histological specimens was observed. Our results indicated the feasibility of MPE samples for PD-L1 detection.

PD-L1 TPS of $\geq 50 \%$ in EGFR mutation patients were reported with $11 \%$ in Gainor et al. study (18). However, lung cancer patients harboring EGFR mutations are associated with lower response to PD-1/PD-L1 inhibitors (usually lower than $5 \%$ in previous studies). Low rates of concurrent PD-L1 expression and $\mathrm{CD} 8^{+}$tumor-infiltrating lymphocytes (TILs) may underlie these results. In present study, $10.3 \%$ EGFR-mutated samples were with PDL1 TPS of $\geq 50 \%$, in contrast, $29.1 \%$ of patients with EGFR wild type were with PD-L1 TPS of $\geq 50 \%$ which consistence with previous study. In another study, Dong et al. found that TP53 mutation significantly activated T-effector and interferon- $\gamma$ signature. And TP53/KRAS comutated subgroup manifested exclusive increased expression 
of $P D-L 1$ mutation burden (19). The reason may due to these two genes altered a group of genes involved in cell cycle regulating, DNA replication and damage repair, which results to a favorable efficacy to immune treatment. However, it is not clear for the correlation between TP53/ $K R A S$ and $P D-L 1$ expression in Dong et al. study. In present study, no significant different was found between TP53/ KRAS mutation. The small number patients may cause the bias.

As a retrospective nature, our study has several limitations. First, only 29 patients were with paired tumor tissue, hence, the accordance between tumor tissue and MPE sample could not fully validated in present study. Second, only the antibody of SP263 was used to examine the PD-L1 expression, which would be preferred for using another antibody to validate the results. In addition, although the $25 \%$ of TPS was recommended as cut-off value for durvalumab study (20). However, in the MYSTIC study, the data showed no more benefit for durvalumab than chemotherapy (21). Hence, $50 \%$ may be a preferable cut-off value regardless different antibody. For the purpose of comparison with other antibody, the $50 \%$ TPS was used in present study. Thirdly, no PD-1/PD-L1 inhibitors are approved in China, our data could not be examined in clinics. In additions, NGS in present study was not based on whole exome sequencing, the results based on 416 genes may not well represent the real TMB level, the relationship between PD-L1 and TMB needs to be investigated in future study. Last but not least, only 123 patients were collected in present study, hence, the correlation between rare oncogene mutations and PD-L1 expression was not fully investigate and the results might be affected.

In summary, our data suggests that MPE samples is feasible for PD-L1 IHC analysis. The PD-L1 levels of MPE cell blocks were comparable with paired tumor tissues, however, heterogeneity was found between these two media. Gene alterations based on NGS of MPE samples could contribute to select the samples that with different PD-L1 expression.

\section{Acknowledgments}

Funding: This work was supported by the National Natural Science Foundation of China (grant no: 81802276).

\section{Footnote}

Conflicts of Interest: All authors have completed the ICMJE uniform disclosure form (available at http://dx.doi. org/10.21037/jtd.2020.02.06). The authors have no conflicts of interest to declare.

Ethical Statement: The authors are accountable for all aspects of the work in ensuring that questions related to the accuracy or integrity of any part of the work are appropriately investigated and resolved. The study was approved by Zhejiang Cancer Hospital Ethics Committee (IRB2014-03-032). Written informed consent was obtained from all participants.

Open Access Statement: This is an Open Access article distributed in accordance with the Creative Commons Attribution-NonCommercial-NoDerivs 4.0 International License (CC BY-NC-ND 4.0), which permits the noncommercial replication and distribution of the article with the strict proviso that no changes or edits are made and the original work is properly cited (including links to both the formal publication through the relevant DOI and the license). See: https://creativecommons.org/licenses/by-nc-nd/4.0/.

\section{References}

1. Mok TS, Wu YL, Thongprasert S, et al. Gefitinib or carboplatin-paclitaxel in pulmonary adenocarcinoma. $\mathrm{N}$ Engl J Med 2009;361:947-57.

2. Maemondo M, Inoue A, Kobayashi K, et al. Gefitinib or chemotherapy for non-small-cell lung cancer with mutated EGFR. N Engl J Med 2010;362:2380-8.

3. Mitsudomi T, Morita S, Yatabe Y, et al. Gefitinib versus cisplatin plus docetaxel in patients with non-small-cell lung cancer harbouring mutations of the epidermal growth factor receptor (WJTOG3405): an open label, randomised phase 3 trial. Lancet Oncol 2010;11:121-8.

4. Wu YL, Zhou C, Liam CK, et al. First-line erlotinib versus gemcitabine/cisplatin in patients with advanced EGFR mutation-positive non-small-cell lung cancer: analyses from the phase III, randomized, open-label, ENSURE study. Ann Oncol 2015;26:1883-9.

5. Rosell R, Carcereny E, Gervais R, et al. Erlotinib versus standard chemotherapy as first-line treatment for European patients with advanced EGFR mutation-positive non-small-cell lung cancer (EURTAC): a multicentre, open-label, randomised phase 3 trial. Lancet Oncol 2012;13:239-46.

6. Shi YK, Wang L, Han BH, et al. First-line icotinib versus cisplatin/pemetrexed plus pemetrexed maintenance therapy 
for patients with advanced EGFR mutation-positive lung adenocarcinoma (CONVINCE): a phase 3, open-label, randomized study. Ann Oncol 2017;28:2443-50.

7. Reck M, Rodriguez-Abreu D, Robinson AG, et al. Pembrolizumab versus Chemotherapy for PD-L1Positive Non-Small-Cell Lung Cancer. N Engl J Med 2016;375:1823-33.

8. Fehrenbacher L, Spira A, Ballinger M, et al. Atezolizumab versus docetaxel for patients with previously treated non-small-cell lung cancer (POPLAR): a multicentre, open-label, phase 2 randomised controlled trial. Lancet 2016;387:1837-46.

9. Chalmers ZR, Connelly CF, Fabrizio D, et al. Analysis of 100,000 human cancer genomes reveals the landscape of tumor mutational burden. Genome Med 2017;9:34.

10. Sacher AG, Gandhi L. Biomarkers for the Clinical Use of PD-1/PD-L1 Inhibitors in Non-Small-Cell Lung Cancer: A Review. JAMA Oncol 2016;2:1217-22.

11. Rimm DL, Han G, Taube JM, et al. A Prospective, Multi-institutional, Pathologist-Based Assessment of 4 Immunohistochemistry Assays for PD-L1 Expression in Non-Small Cell Lung Cancer. JAMA Oncol 2017;3:1051-8.

12. Kerr KM, Nicolson MC. Non-Small Cell Lung Cancer, PD-L1, and the Pathologist. Arch Pathol Lab Med 2016;140:249-54.

13. Sholl LM, Aisner DL, Allen TC, et al. Programmed Death Ligand-1 Immunohistochemistry--A New Challenge for Pathologists: A Perspective From Members of the Pulmonary Pathology Society. Arch Pathol Lab Med 2016;140:341-4.

14. Hirsch FR, Mcelhinny A, Stanforth D, et al. PDL1 Immunohistochemistry Assays for Lung Cancer:

Cite this article as: Song Z, Cheng G, Zhang Y. PD$\mathrm{L} 1$ expression in malignant pleural effusion samples and its correlation with oncogene mutations in non-small cell lung cancer. J Thorac Dis 2020;12(4):1385-1392. doi: 10.21037/ jtd.2020.02.06
Results from Phase 1 of the Blueprint PD-L1 IHC Assay Comparison Project. J Thorac Oncol 2017;12:208-22.

15. Ilie M, Khambata-Ford S, Copie-Bergman C, et al. Use of the 22C3 anti-PD-L1 antibody to determine PD-L1 expression in multiple automated immunohistochemistry platforms. PLoS One 2017;12:e0183023.

16. Rangachari D, VanderLaan PA, Shea M, et al. Correlation between Classic Driver Oncogene Mutations in EGFR, ALK, or ROS1 and 22C3-PD-L1 $250 \%$ Expression in Lung Adenocarcinoma. J Thorac Oncol 2017;12:878-83.

17. Herbst RS, Baas P, Kim DW, et al. Pembrolizumab versus docetaxel for previously treated, PD-L1-positive, advanced non-small-cell lung cancer (KEYNOTE-010): a randomised controlled trial. Lancet 2016;387:1540-50.

18. Gainor JF, Shaw AT, Sequist LV, et al. EGFR Mutations and ALK Rearrangements Are Associated with Low Response Rates to PD-1 Pathway Blockade in Non-Small Cell Lung Cancer: A Retrospective Analysis. Clin Cancer Res 2016;22:4585-93.

19. Dong ZY, Zhong WZ, Zhang XC, et al. Potential Predictive Value of TP53 and KRAS Mutation Status for Response to PD-1 Blockade Immunotherapy in Lung Adenocarcinoma. Clin Cancer Res 2017;23:3012-24.

20. Powles T, O'donnell PH, Massard C, et al. Efficacy and Safety of Durvalumab in Locally Advanced or Metastatic Urothelial Carcinoma: Updated Results From a Phase 1/2 Open-label Study. JAMA Oncol 2017;3:e172411.

21. Planchard D, Yokoi T, Mccleod MJ, et al. A Phase III Study of Durvalumab (MEDI4736) With or Without Tremelimumab for Previously Treated Patients With Advanced NSCLC: Rationale and Protocol Design of the ARCTIC Study. Clin Lung Cancer 2016;17:232-236.e1. 
A
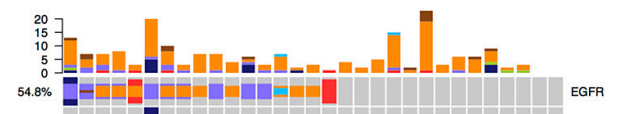

\begin{tabular}{l|l|l|l|l|}
$48.4 \%$ & $=-$ & - & -
\end{tabular}

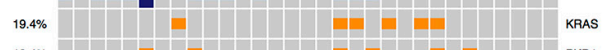

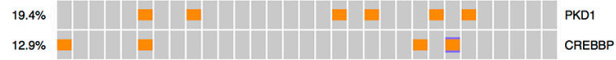

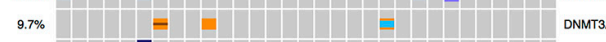

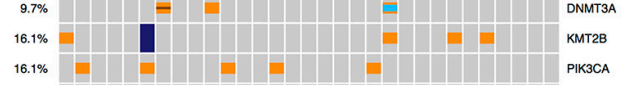

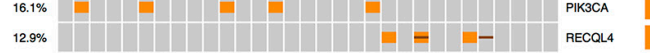

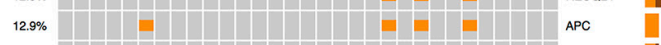

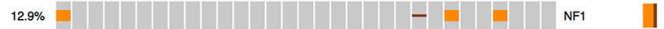

\begin{tabular}{l|l|l|l|l|l|l|l|l|l|}
$12.9 \%$ & RAC1
\end{tabular}

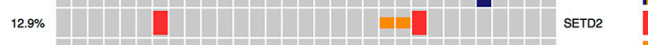

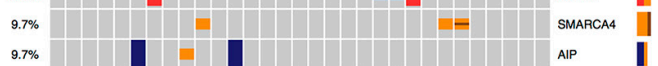

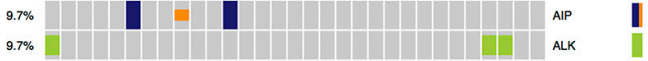

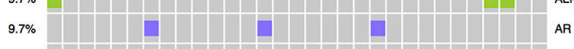

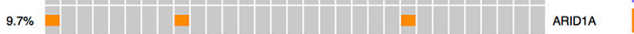

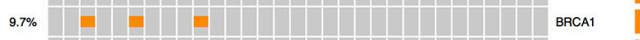

\begin{tabular}{l|l||l||l||l|}
$9.7 \%$ & CDK12 \\
\hline
\end{tabular}

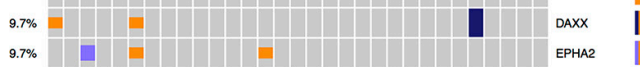

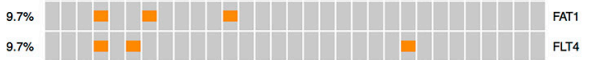

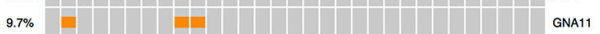

\begin{tabular}{l|l|l|l|l|l|l|l|l|l|l|}
\hline $9.7 \%$ & GNAS \\
\hline
\end{tabular}

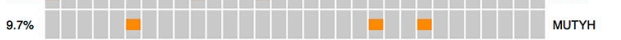

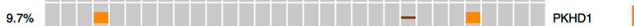

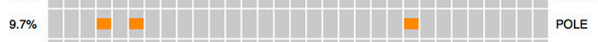

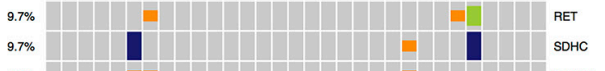

\begin{tabular}{l|l|l|l|l|l|l|l|l|l|}
$9.7 \%$ & SDHC \\
\hline $9.7 \%$ & & SMAD4 \\
\hline
\end{tabular}

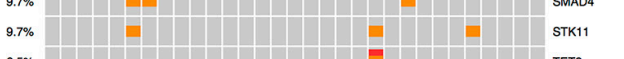

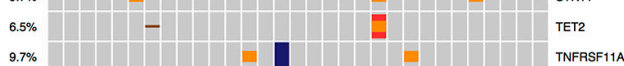

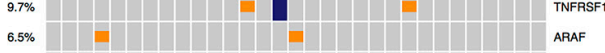

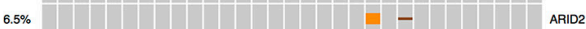
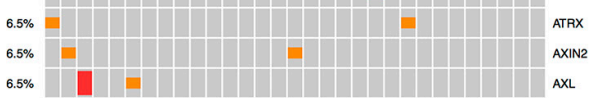

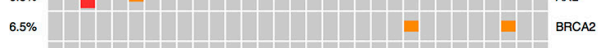

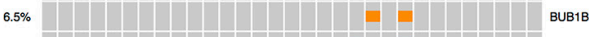

\begin{tabular}{l||l|||c||c|c|c|}
$6.5 \%$ & CBLB \\
\hline
\end{tabular}
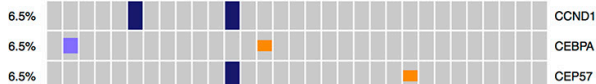

\begin{tabular}{l|l|l|l|l|l|l|l|l|l|l|l|l|} 
CHD4 \\
\hline $6.5 \%$
\end{tabular}

$6.5 \%$

$6.5 \%$

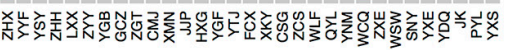

B

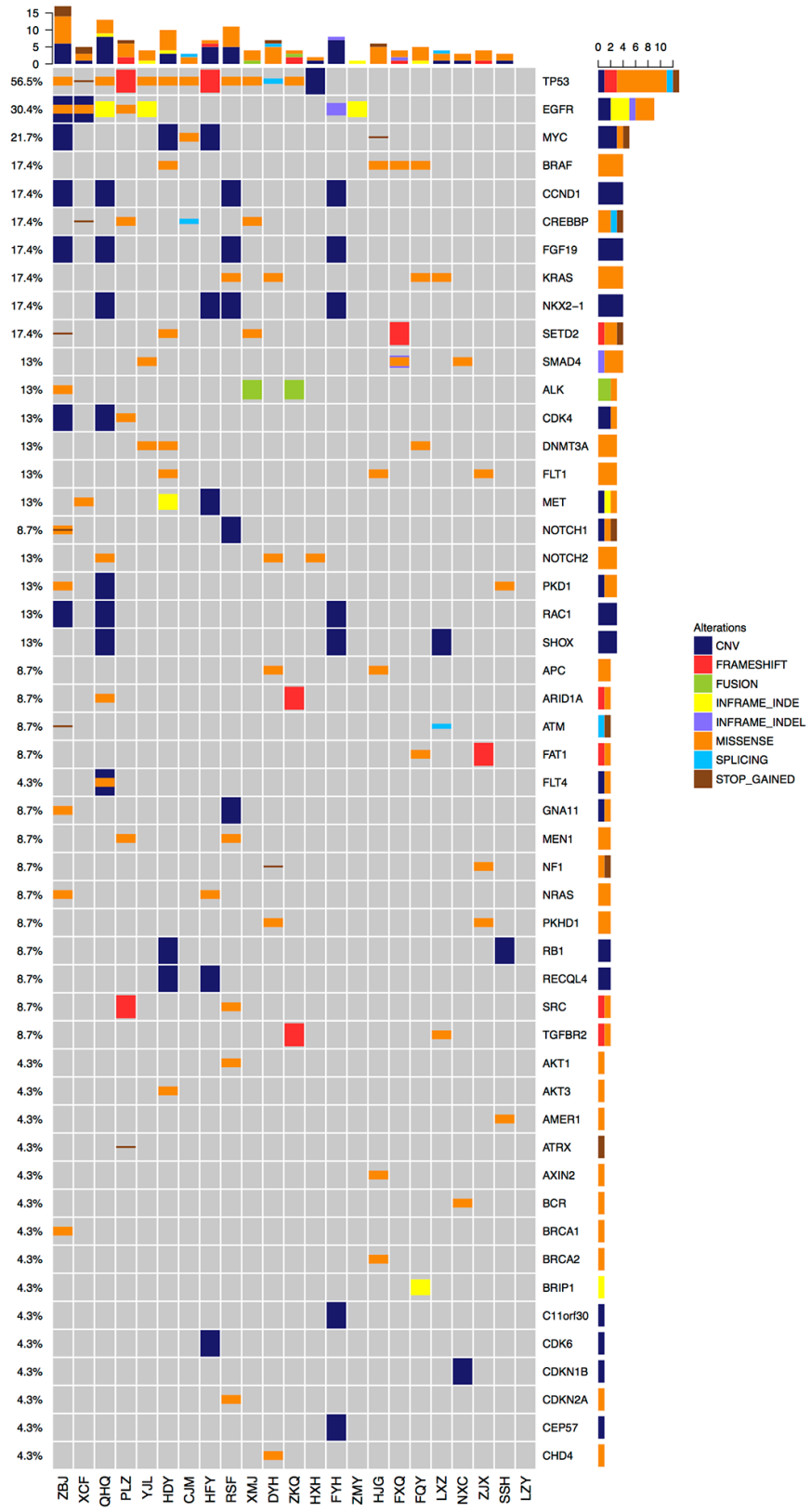

Figure S1 Top 50 genes in patients with PD-L1 TPS $<50 \%$ (A) and with PD-L1 TPS $\geq 50 \%$ (B). PD-L1, programmed death ligand 1; TPS, tumor proportion score. 


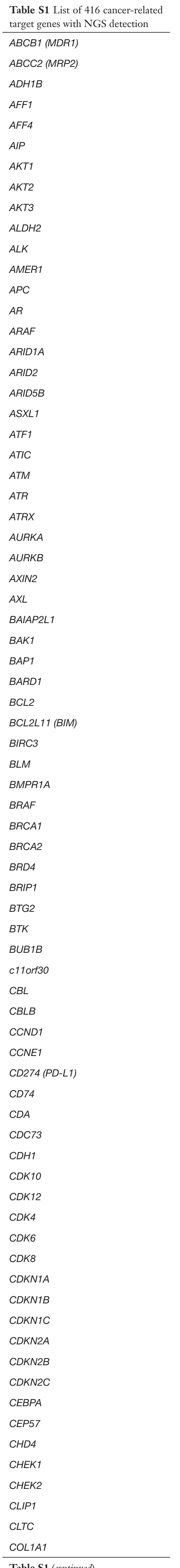

\begin{tabular}{|c|}
\hline Table S1 (continued) \\
\hline CREB1 \\
\hline CREBBP \\
\hline CRKL \\
\hline CSF1R \\
\hline CTCF \\
\hline CTLA4 \\
\hline CTNNB1 \\
\hline CXCR4 \\
\hline CYLD \\
\hline CYP19A1 \\
\hline CYP2A6 \\
\hline СYР2B6*6 \\
\hline CYP2C19*2 \\
\hline CYP2C9*3 \\
\hline CYP2D6*3 \\
\hline CYP2D6*4 \\
\hline CYP2D6*5 \\
\hline CYP2D6*6 \\
\hline CYP2D6*7 \\
\hline CYP2D6*11 \\
\hline CYP2D6*12 \\
\hline CYP2D6*14 \\
\hline СУРЗА4*4 \\
\hline СYРЗА5*1 \\
\hline СУРЗА5*3 \\
\hline$D A X X$ \\
\hline DCTN1 \\
\hline DDIT3 \\
\hline DDR2 \\
\hline DENND1A \\
\hline DHFR \\
\hline DICER1 \\
\hline DNMT3A \\
\hline$D P Y D$ \\
\hline DUSP2 \\
\hline EGFR \\
\hline EML4 \\
\hline EP300 \\
\hline EPAS1 \\
\hline EPCAM \\
\hline EPHA2 \\
\hline EPHA3 \\
\hline EPS15 \\
\hline ERBB2 (HER2) \\
\hline ERBB3 \\
\hline ERBB4 \\
\hline ERC1 \\
\hline ERCC1 \\
\hline ERCC2 \\
\hline ERCC3 \\
\hline ERCC4 \\
\hline ERCC5 \\
\hline$E R G$ \\
\hline ESR1 \\
\hline ETV1 \\
\hline ETV4 \\
\hline ETV6 \\
\hline EWSR1 \\
\hline EXT1 \\
\hline EXT2 \\
\hline EZH2 \\
\hline EZR \\
\hline FANCA \\
\hline FANCC \\
\hline FANCD2 \\
\hline FANCE \\
\hline FANCF \\
\hline FANCG \\
\hline FANCL \\
\hline FAT1 \\
\hline FBX1 \\
\hline FBXW7 \\
\hline FEV \\
\hline FGF19 \\
\hline FGFR1 \\
\hline
\end{tabular}

\begin{tabular}{|c|}
\hline Table S1 (continued) \\
\hline FGFR2 \\
\hline FGFR3 \\
\hline FGFR4 \\
\hline$F H$ \\
\hline FLCN \\
\hline$F L / 1$ \\
\hline FLT1 (VEGFR1) \\
\hline FLT3 \\
\hline FLT4 \\
\hline GATA1 \\
\hline GATA2 \\
\hline GATA3 \\
\hline GATA4 \\
\hline GATAG \\
\hline GNA11 \\
\hline GNAQ \\
\hline GNAS \\
\hline GOLGA5 \\
\hline GOPC \\
\hline GRIN2A \\
\hline GRM3 \\
\hline GSTM1 \\
\hline GSTP1 \\
\hline GSTT1 \\
\hline HDAC2 \\
\hline HGF \\
\hline HIP1 \\
\hline HLA-A \\
\hline HNF1A \\
\hline HNF1B \\
\hline HRAS \\
\hline HSD3B1 \\
\hline IDH1 \\
\hline IDH2 \\
\hline IGF1R \\
\hline IGF2 \\
\hline IKBKE \\
\hline IKZF1 \\
\hline IKZF3 \\
\hline IL7R \\
\hline INPP4B \\
\hline INPP5D \\
\hline IRF2 \\
\hline JAK1 \\
\hline JAK2 \\
\hline JAK3 \\
\hline JUN \\
\hline KDM5A \\
\hline KDM6A \\
\hline KDR (VEGFR2) \\
\hline KIF5B \\
\hline KIT \\
\hline KITLG \\
\hline KLC1 \\
\hline KLLN \\
\hline КMT2A \\
\hline КMT2B \\
\hline KRAS \\
\hline KTN1 \\
\hline LHCGR \\
\hline LMO1 \\
\hline LRIG3 \\
\hline LYN \\
\hline LZTR1 \\
\hline MAP2K1 (MEK1) \\
\hline МАР2K2 (MEК2) \\
\hline MAP2K4 \\
\hline MAPЗK 1 \\
\hline MAP4K3 \\
\hline MAX \\
\hline MCL1 \\
\hline MDM2 \\
\hline MDM4 \\
\hline MED12 \\
\hline MEF2B \\
\hline
\end{tabular}

\begin{tabular}{|c|}
\hline Table S1 (continued) \\
\hline MEN1 \\
\hline MET \\
\hline MGMT \\
\hline MITF \\
\hline MLH1 \\
\hline MLH3 \\
\hline MLLT1 \\
\hline MLLT1O \\
\hline MLLT3 \\
\hline MLLT4 \\
\hline$M P L$ \\
\hline MRE11A \\
\hline MSH2 \\
\hline MSH3 \\
\hline MSH6 \\
\hline MTHFR \\
\hline MTOR \\
\hline MUTYH \\
\hline MYC \\
\hline MYCL \\
\hline MYCN \\
\hline MYD88 \\
\hline NAT1 \\
\hline NBN \\
\hline NCOA4 \\
\hline NF1 \\
\hline NF2 \\
\hline NFKBIA \\
\hline$N K \times 2-1$ \\
\hline $\mathrm{NOTCH} 1$ \\
\hline NOTCH2 \\
\hline NPM1 \\
\hline NQO1 \\
\hline NR4A3 \\
\hline NRAS \\
\hline NSD1 \\
\hline NTRK1 \\
\hline РАКЗ \\
\hline PALB2 \\
\hline PALLD \\
\hline PARK2 \\
\hline PARP1 \\
\hline PARP2 \\
\hline PAX5 \\
\hline PBRM1 \\
\hline PCDH11Y \\
\hline PDCD1 (PD1) \\
\hline PDCD1LG2 (PD-L2) \\
\hline$P D E 11 A$ \\
\hline PDGFRA \\
\hline PDGFRB \\
\hline$P D K 1$ \\
\hline$P G R$ \\
\hline PHOX2B \\
\hline PIКЗСЗ \\
\hline PIK3CA \\
\hline PIK3R1 \\
\hline PIK3R2 \\
\hline PKD1 \\
\hline PKD2 \\
\hline PKHD1 \\
\hline PLAG1 \\
\hline PLK1 \\
\hline PMS1 \\
\hline PMS2 \\
\hline POLD1 \\
\hline POLE \\
\hline POLH \\
\hline POT1 \\
\hline POU5F1 \\
\hline PPP2R1A \\
\hline PRDM1 \\
\hline PRF1 \\
\hline PRKACA \\
\hline PRKAR1A \\
\hline
\end{tabular}

\begin{tabular}{|c|c|}
\hline Table S1 (continued) & Table S1 (continued) \\
\hline PRKCl & TMPRSS2 \\
\hline PRSS1 & TNFAIP3 \\
\hline PTCH1 & TNFRSF11A \\
\hline PTEN & TNFRSF14 \\
\hline PTK2 & TNFRSF19 \\
\hline PTPN11 & TNFSF11 \\
\hline PTPRD & TOP1 \\
\hline QKI & TOP2A \\
\hline RAC1 & TP53 \\
\hline RAD50 & TPM3 \\
\hline RAD51 & TPM4 \\
\hline RAD51C & TPMT*2 \\
\hline RAD51D & TPMT $^{\star} 3$ \\
\hline RAF1 & TPMT 4 \\
\hline RARA & TPMT*5 \\
\hline$R B 1$ & TPMT*6 \\
\hline RECQL4 & TPMT*7 \\
\hline RET & TPMT*10 \\
\hline RHOA & TRIM24 \\
\hline RICTOR & TRIM27 \\
\hline RNF146 & TRIM33 \\
\hline RNF43 & TSC1 \\
\hline ROS1 & TSC2 \\
\hline RPTOR & TSHR \\
\hline RRM1 & TTF1 \\
\hline RTEL1 & TUBB3 \\
\hline RUNX1 & TYMS \\
\hline SBDS & UGT1A1 \\
\hline$S D C 4$ & VEGFA \\
\hline SDHA & VHL \\
\hline SDHAF2 & WAS \\
\hline SDHB & WISP3 \\
\hline$S D H C$ & WRN \\
\hline SDHD & WT1 \\
\hline SEPT9 & $X P A$ \\
\hline SERP2 & $X P C$ \\
\hline SETBP1 & $X R C C 1$ \\
\hline SETD2 & YAP1 \\
\hline$S F 3 B 1$ & ZNF2 \\
\hline SGK1 & ZNF217 \\
\hline$S H 2 D 1 A$ & ZNF444 \\
\hline SHOX & ZNF703 \\
\hline SLC34A2 & NGS, next generat \\
\hline
\end{tabular}


Table S2 Comparison of clinical characteristics of PD-L1 TPS $\geq 50 \%$ versus TPS $<50 \%$

\begin{tabular}{|c|c|c|c|}
\hline Variable & PD-L1 TPS $\geq 50 \%$ & PD-L1 TPS <50\% & $\mathrm{P}$ \\
\hline Male & 17 & 48 & \\
\hline Female & 6 & 52 & \\
\hline Age, years & & & 0.85 \\
\hline$\geq 65$ & 9 & 37 & \\
\hline Smoking history & & & 0.01 \\
\hline Yes & 15 & 36 & \\
\hline No & 8 & 64 & \\
\hline M1b & 8 & 42 & \\
\hline Chemotherapy history & & & 0.33 \\
\hline Yes & 5 & 32 & \\
\hline No & 18 & 68 & \\
\hline Performance status & & & 0.33 \\
\hline $0-1$ & 19 & 92 & \\
\hline 2 & 4 & 8 & \\
\hline
\end{tabular}

PD-L1, programmed death ligand 1; TPS, tumor proportion score. 